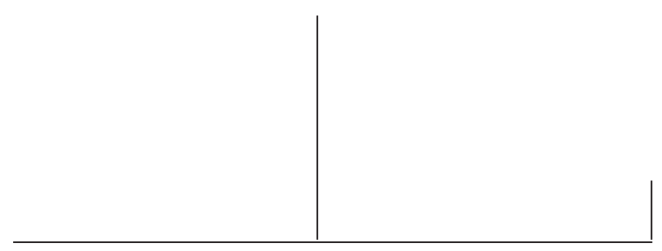

Rev. Latinoam. Psicopat. Fund., VII, 4, 165-191

\title{
Os dispositivos de lazer no contexto da reforma psiquiátrica brasileira: - Clube do Lazer e Cidadania Colônia, um estudo de caso
}

\author{
Michèle Malheiro Borges de Aquino \\ Maria Tavares Cavalcanti
}

\begin{abstract}
O Clube de Lazer e Cidadania Colônia funciona desde janeiro de 2000 no Instituto Municipal de Assistência à Saúde Juliano Moreira - IMASJM, na cidade do Rio de Janeiro, sendo um dispositivo criado a partir dos princípios que norteiam o movimento de reforma psiquiátrica no Brasil. Assim, ele se insere nos diversos serviços e práticas que se fizeram necessários a partir do movimento de desinstitucionalização psiquiátrica em nosso país. Este trabalho procura aplicar a teoria sociológica do lazer - encontrada em autores como Joffre Dumazedier, Domenico de Masi e Milton Santos -, no campo da saúde mental. São definidos o lazer e o semi-lazer destacando-se seu papel na sociedade. Há uma abordagem teórica e uma pesquisa qualitativa que analisa as características do lazer para os usuários e membros da equipe.
\end{abstract}

Palavras-chave: Lazer, reforma psiquiátrica, reabilitação psicossocial, serviço extra-hospitalar 


\section{Introdução}

Este trabalho se baseia na experiência do Clube de Lazer e Cidadania Colônia. A questão que motiva a nossa investigação é pensar a inserção e a prática de lazer para os usuários de serviços de saúde mental em geral e especificamente do Instituto Municipal de Assistência à Saúde Juliano Moreira - IMASJM. Além disso, gostaríamos de discutir quais características do conceito de lazer, originadas na sociologia do trabalho, poderiam ser aproveitadas no campo da saúde mental.

Constatamos que através do instrumento do lazer, relações afetivas de outra ordem, diferentes daquelas estabelecidas no mundo asilar, podem ser desenvolvidas e incrementadas na vida destas pessoas.

Trata-se de assumir uma nova valorização para o tempo livre que seja distinta daquela do ócio forçado a que o asilo submete as pessoas. Um tempo livre, dedicado ao ócio sim, mas um ócio no qual o papel de doente mental é relativizado, criando-se um tempo a ser vivido prazerosamente.

Indicamos, desde já, que em nossa prática no Clube de Lazer levamos em conta a conceituação do sociólogo Joffre Dumazedier (1999) que:

... destina ao vocábulo lazer o único conteúdo do tempo orientado para a realização da pessoa com fim último. Este tempo é outorgado ao indivíduo pela sociedade quando este se desempenhou, segundo as normas sociais do momento, de suas obrigações profissionais, familiares, sócio-espirituais e sociopolíticas, o indivíduo se libera ao seu gosto da fadiga descansando, do tédio divertindo-se, da especialização funcional desenvolvendo de maneira interessada as capacidades de seu corpo ou de seu espírito. Este tempo disponível não é resultado de uma decisão do indivíduo; é, primeiramente, o resultado de uma evolução da economia e da sociedade, é um novo valor social da pessoa que se traduz por um novo direito social, o direito dela dispor de um tempo cuja finalidade é, antes, a auto-satisfação. (p. 92) 
As condições de vida de nossa clientela são tão mais graves, uma vez que não há em seu cotidiano a dimensão do trabalho e da família. Poderíamos até mesmo ingenuamente pensar que viveriam apenas no ócio, e portanto em uma vida bastante propícia ao lazer. No entanto, o que encontramos na situação de uma clientela institucionalizada em média há 37 anos é uma vida completamente empobrecida decorrente dos anos de institucionalização. Os usuários institucionalizados, como os moradores do IMASJM, construíram suas subjetividades em grande parte dentro de instituições totais. ${ }^{1}$ Trata-se inicialmente de aproximarmo-nos desta subjetividade, que está armazenada em sua memória, no seu esquema corporal, e através da prática de lazer criar novas possibilidades de estar no mundo para essa população.

Neste trabalho caracterizaremos inicialmente a Reforma Psiquiátrica, o IMASJM e o Clube de Lazer. Em seguida nos deteremos mais de perto no conceito de lazer. Munidos deste arsenal apresentaremos então alguns dos resultados da pesquisa qualitativa realizada com usuários e técnicos da equipe do Clube com vistas a apreendermos a aplicabilidade dos conceitos de lazer no campo da saúde mental.

Parte I - Asilo, Colônia e Reforma Psiquiátrica

A Reforma Psiquiátrica é um processo histórico de crítica e prática cujos objetivos e estratégias são o questionamento e a elaboração de propostas de transformação do modelo asilar clássico, a desinstitucionalização e a possibilidade de recuperação de uma clínica psiquiátrica bem feita. $\mathrm{O}$ asilo caracteriza-se pelo abandono de toda e qualquer terapêutica. A Reforma, ao apontar para as conseqüências desse abandono, propõe a comunidade como o lugar mais adequado ao cuidado com o paciente psiquiátrico, indicando a diversidade de olhares e práticas como o fundamental para um bom cuidado psiquiátrico. É neste sentido que o lazer passa a fazer parte do vocabulário da reforma.

\section{A Reforma Psiquiátrica Brasileira}

O movimento de Reforma Psiquiátrica no Brasil inspirou-se em grande parte na psiquiatria democrática italiana. $\mathrm{O}$ grande marco da reforma italiana se deu com Franco Basaglia, inicialmente em Gorisia, e posteriormente em Trieste, quando na

1. Ver definição de Instituição Total Parte II deste trabalho. 


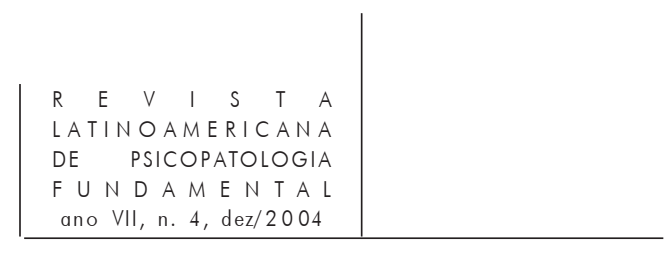

década de 1970 passou a dirigir um hospital com 1200 leitos iniciando um processo de transformação desse hospital com vistas ao seu fechamento:

... paralelamente a este movimento de transformação do interior dos hospitais psiquiátricos, busca-se uma aproximação com a comunidade, coerentemente à idéia de que o projeto da instituição só pode ser exterior. Esta aproximação se faz pelos dois lados, tanto através do convite para que a população participe das atividades do hospital, quanto pela saída de pacientes que passam a visitar suas famílias durante o dia, acompanhados de enfermeiros. A partir de 1976 iniciase a construção gradual dos centros externos. (...) de forma que em 1980 já existem sete centros de saúde mental cobrindo todo o território da cidade de Trieste e o hospital psiquiátrico é fechado. (Cavalcanti, 1992, p. 134)

No Brasil, surge nos anos 1980, a indicação da necessidade urgente de uma reformulação da política de assistência psiquiátrica movida por alguns atores, entre os quais se destaca, o Movimento dos Trabalhadores de Saúde Mental que é: "o ator a partir do qual originalmente emergem as propostas de reformulação do sistema assistencial e no qual se consolidam o pensamento crítico ao saber psiquiátrico" (Amarante, 1995, p. 57). A sociedade, e particularmente os trabalhadores do campo de saúde mental, passam a questionar o crescimento irregular e a qualidade dos serviços prestados nas clínicas psiquiátricas contratadas pelo Sistema Único de Saúde (SUS) e apontam para a complexidade da doença mental e a necessidade de mecanismos de atuação outros no sofrimento de tais pacientes.

De acordo com Schechtman et. al. (1999) na década de 1990 tornam-se públicas as violações dos direitos humanos dos pacientes internos em hospitais psiquiátricos, o que acabou por demonstrar a necessidade da construção de uma Política Nacional de Saúde Mental, atenta às contradições existentes no campo.

Foi assim que profissionais da saúde que trabalhavam diretamente com doentes mentais, começaram a experimentar novas abordagens na qual se consideravam também o ambiente e a cultura dos pacientes, e não apenas o seu "corpo doente".

Em 1986 ocorreu a VIII Conferência Nacional de Saúde que propunha "paralelamente resoluções específicas para a área de saúde mental, ratificando o combate ao modelo asilar e incluindo questões ligadas à mudança da legislação psiquiátrica em vigor" (Gomes, 1999, p. 94).

Esse evento resultou na I Conferência Nacional de Saúde Mental, em 1987, e no Projeto de Lei no 3.657/89, de autoria do deputado Paulo Delgado. ${ }^{2}$

2. O projeto de Lei 3.657/89 desencadeou uma série de reflexões a respeito da loucura em todo país. 
Encontramos de igual modo na Declaração de Caracas $^{3}$ a valorização dos aspectos sociais e culturais, bem como o redirecionamento da assistência em saúde mental para a América Latina, cujos objetivos principais são: 1) superação do hospital psiquiátrico como serviço central da atenção em saúde mental; 2) os recursos utilizados devem respeitar os direitos dos pacientes; 3) criação de uma rede de atenção psicossocial, extra-hospitalar, de base comunitária.

Em junho de 1987 surgem as propostas dos Centros de Atenção Psicossocial (Caps) e Núcleo de Atenção Psicossocial (Naps) como uma alternativa organizada e estruturada de atendimento extra-hospitalar. ${ }^{4}$ Em 1992 inicia-se a desativação de hospitais psiquiátricos e redução de leitos. A II Conferência Nacional de Saúde Mental indica como prioridade a construção de uma "rede de atenção em saúde mental, [bem como] a transformação e cumprimento de leis, direito à atenção e direito à cidadania [dos doentes mentais]" (Gomes, 1999, p. 101).

Esta proposta deve ser seguida em conjunto com os familiares e usuários dos serviços de saúde mental.

De acordo com Jairo Goldberg (1996), o Caps foi criado com o objetivo de ser uma referência para o paciente e para a família, articulando práticas já instituídas de psicoterapia, de grupos e de medicação com outras práticas capazes de valorizar o paciente, tais como: reunião de usuários e atividades expressivas realizadas em um ambiente terapêutico.

Em síntese, a Reforma Psiquiátrica é entendida como uma prática de transformação dos espaços asilares desertificados, trazendo para esses espaços vida, clínica psiquiátrica bem-feita, e, quando possível, transformando esses espaços através de práticas não hospitalares, ou seja, comunitárias; tentando inserir ao máximo o sujeito em seu contexto social, familiar e cultural.

3. A Declaração de Caracas foi aprovada em 14 de novembro de 1990. Seu objetivo era apontar para a necessidade de uma reestruturação da assistência psiquiátrica, uma vez que a psiquiatria convencional e o hospital psiquiátrico não conseguiam desenvolver uma prática que atendesse as necessidades dos pacientes, e nem fornecer serviços humanos e eficazes.

4. Em 29 de janeiro de 1992, foi publicada a Portaria no 224 que estabelece as diretrizes e normas sobre a organização dos serviços de Saúde Mental. Os CAPS/NAPS, dentre outras atribuições, "oferecem atendimento de cuidados intermediários entre o regime ambulatorial e a internação hospitalar”. Legislação em Saúde Mental 1990-2000, p. 57. Em 19 de fevereiro de 2002, o Ministro da Saúde, considerando a necessidade de atualização da Portaria no 224, aprova a Portaria no 336 e estabelece que: "os Centro de Atenção Psicossocial poderão constituir-se nas seguintes modalidades de serviços: CAPS I, CAPS II e CAPS III definidos por ordem crescente de porte/complexidade e abrangência populacional [...] Os CAPS deverão constituir-se em serviço ambulatorial de atenção diária que funcione segundo a lógica territorial”. Legislação em Saúde Mental 1990-2002, p. 111. 


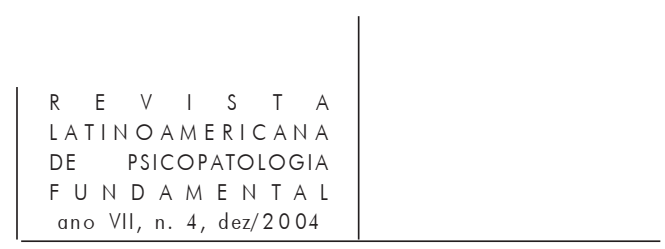

Enquanto movimento, a Reforma Psiquiátrica começou a operar no IMASJM a partir do início da década de 1980.

Vejamos, antes de entrar propriamente nas questões envolvidas com o lazer - objeto deste estudo - um pouco da trajetória desta instituição.

\section{A Colônia Juliano Moreira: da origem à Reforma Psiquiátrica}

Nas terras da antiga fazenda do Engenho Novo da Curicica, de propriedade do Barão da Taquara, foi fundada, em 1924, a Colônia de Alienados de Jacarepaguá, na cidade do Rio de Janeiro. As construções conservadas do século XVIII e XIX, abrigaram a estrutura do asilo, cuja primeira função foi receber os internos homens vindos dos asilos de São Bento e Conde de Mesquita, na Ilha do Governador.

De acordo com André Milagres (2002), Juliano Moreira, médico, diretor da Assistência de Alienados de 1903 a 1931, apontava uma nova visão da psiquiatria:

... o trabalho teria uma função benéfica na recuperação dos então chamados "alienados mentais". Além disso, desenvolvia-se a noção de que os alienados, considerados desviantes sociais, poderiam ser ressocializados através do convívio com as pessoas ditas normais e moralmente idôneas. (Milagres, 2002, p. 39)

Esta premissa refletiu uma nova forma de terapêutica que aliava o trabalho agrícola produtivo a uma convivência hetero-familiar, facilitada pela construção de casas funcionais onde residiam os funcionários da instituição, e que mais tarde iriam acolher seus filhos e netos, estabelecendo uma nova configuração no espaço das terras da Colônia.

De acordo com Amarante (1982), a assistência hetero-familiar consistia em:

Uma reprodução da vida comum e da liberdade, a assistência hetero-familiar empenha-se em extrair do asilo suas características de cárcere, de disciplina de caserna. Paradoxalmente, ao mesmo tempo em que objetiva compromissar a sociedade numa assistência menos coercitiva, mais sutil, para poder internalizarlhe os ensinamentos normativos da psiquiatria, existe, na verdade, como mais um recurso do próprio asilo. Atrai famílias para o espaço da reclusão, no lugar de manter os doentes no ambiente de origem. A transferência das famílias para o hospício, ou a transferência de alienados para suas casas, faz parte do exercício. (p. 101)

A expansão do dispositivo hospital-colônia, acaba por expandir o campo asilar, criando locais de tratamento afastados do perímetro urbano, no sentido oposto à expansão da cidade. O dispositivo que propunha um modelo inovador 
e humanizado de tratamento acaba resultando na cronificação dos pacientes e na superlotação do hospital.

A partir de junho de 1996, a então denominada Colônia Juliano Moreira foi municipalizada e começou a ser implantado o Programa de Reabilitação Psicossocial voltado para a desinstitucionalização, sendo desmembrada em três instituições: o Instituto Municipal de Assistência à Saúde Juliano Moreira (IMASJM), o Hospital Municipal Jurandyr Manfredini (HMJM) e o Hospital Municipal Álvaro Ramos.

A municipalização da Colônia acompanha as diretrizes de descentralização do Sistema Único de Saúde (SUS) e de reorientação do modelo assistencial em Saúde Mental.

Atualmente o IMASJM é formado pelos núcleos: Teixeira Brandão, Franco da Rocha, Ulisses Vianna, Rodrigues Caldas e Agrícola (prestes a ser desativado) e pelo Centro de Reabilitação e Integração Social (CRIS). As estruturas das enfermarias têm sido, na medida do possível, transformadas em Lares de Acolhimento. ${ }^{5}$ Com objetivo de aproximar a comunidade e usuários, o IMASJM comporta o Museu Bispo do Rosário e o Clube de Lazer e Cidadania Colônia.

De acordo com o Cadastro de Pacientes do IMASJM do mês de maio de 2004, o IMASJM cuida de 148 usuários no Núcleo Franco da Rocha, 276 usuários no Núcleo Teixeira Brandão, 144 usuários no Núcleo Ulisses Vianna, 110 usuários no Núcleo Rodrigues Caldas e 29 usuários no Núcleo Agrícola. No CRIS há 21 moradores internos e 53 moradores em Residências Terapêuticas. No total, portanto, o IMASJM cuida de 781 pacientes em regime de internação e moradia assistida.

\section{Parte II - O Clube de Lazer inserido na Reforma Psiquiátrica do Brasil}

\section{O Clube de Lazer e Cidadania Colônia}

O Clube de Lazer e Cidadania Colônia é um espaço de mediação entre a instituição e a cidade, proporcionando a seus usuários uma inserção assistida no ambiente urbano dentro de uma prática de Reabilitação Psicossocial, conforme a define Saraceno (1996) “... um processo de reconstrução, um exercício pleno da cidadania, e também de plena contratualidade nos três grandes cenários: habitat, rede social e trabalho com valor social" (Saraceno, 1996, p. 16).

5. Os Lares de Acolhimento são enfermarias adaptadas que funcionam com uma estrutura próxima a de uma casa. 


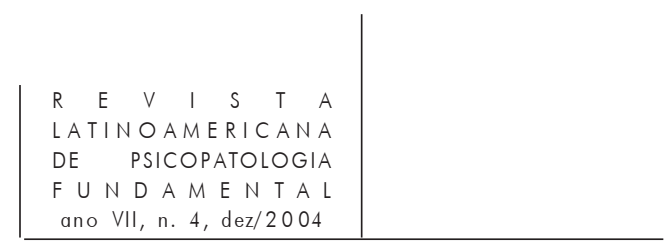

Assim como os Hospitais-Dia e os CAPS abertos com o objetivo de uma proposta de trabalho mais humanizada e se oferecendo como uma alternativa ao isolamento asilar, o Espaço de Lazer também se constitui como mais uma ferramenta nesta direção. Não se trata de uma reabilitação no "sentido ortopédico" como nos alerta Ana Pitta (1996), mas na promoção de eqüidade, ou seja, “... atender igualmente o direito de cada um singularizado e subjetivado (...) um tratado ético-estético" (Pitta, 1996, p. 23).

O Clube é um lugar de encontro, que busca romper com o que Goffman (1999) definiu como Instituição Total.

$\mathrm{O}$ aspecto central das instituições totais pode ser descrito como a ruptura das barreiras que comumente separam essas três esferas da vida. Em primeiro lugar, todos os aspectos da vida são realizados no mesmo local e sob uma única autoridade. Em segundo lugar, cada fase da atividade diária do participante é realizada na companhia imediata de um grupo relativamente grande de outras pessoas, todas elas tratadas da mesma forma e obrigadas a fazer as mesmas coisas em conjunto. Em terceiro lugar, todas as atividades diárias são rigorosamente estabelecidas em horários, pois uma atividade leva, em tempo predeterminado, à seguinte, e toda a seqüência de atividades é imposta de cima, por um sistema de regras. Finalmente, as várias atividades obrigatórias são reunidas num plano racional único, supostamente planejado para atender aos objetivos oficiais da instituição. (p. 17-8)

Podemos pensar que a lógica do Clube rompe com a lógica da instituição total, uma vez que se constitui num lugar no qual os seus membros podem permanecer agradavelmente, por livre opção. O Clube faz parte da Rede de Saúde Mental, e nele a solidariedade é estimulada, a vida fora da esfera institucional psiquiátrica e/ou asilar é incentivada, o entretenimento sendo proposto não para alimentar a permanência dos pacientes no espaço institucional, como critica Saraceno (1999), mas para estimular e apontar para o direito ao lazer fora da instituição, gerando o aumento de sua autonomia vivencial e efetiva.

Por autonomia Tykanori (1996) entende:

... a capacidade de um indivíduo gerar normas, ordens para a sua vida conforme as diversas situações que enfrente (...) somos mais autônomos quanto mais dependentes de tantas mais coisas pudermos ser, pois isto amplia as nossas possibilidades de estabelecer novas normas, novos ordenamentos para a vida. (p. 57)

O Clube constitui um espaço de lazer, onde são oferecidas atividades sociais, físicas e emocionais de entretenimento e formação. Acreditamos que para os técnicos, o espaço de lazer também demanda trabalho, e, como trabalho, precisa de aplicação, treinamento, estudo e dedicação. 
Refletir sobre os objetivos e necessidades de um Clube de Lazer em Saúde Mental requer que avaliemos as nossas opções de lazer, uma vez que fazemos parte dessa construção e estamos inseridos numa sociedade marcada por contradições em que as ofertas são globalizadas, predeterminadas e temos a tarefa de reconhecer nossa cultura, nossa história e nossos desejos, tornando-nos agentes ativos, utilizando o lazer de forma inteligente.

Segundo Domenico de Masi (2001):

... os prazeres das populações urbanas se tornaram fundamentalmente passivos: ver filmes, assistir a partidas de futebol, ouvir rádio e assim por diante. Isso ocorre porque as energias ativas da população estão totalmente absorvidas pelo trabalho. Se as pessoas tivessem mais lazer, voltariam a desfrutar prazeres em que participassem ativamente. (p. 60)

Isto nos remete à desconstrução da relação hierarquizada, tal como se dá no Clube, diferentemente do que se processa na esfera asilar. A equipe técnica participa das atividades de um lugar diferenciado, enquanto responsável pelo cuidado, mas isso não impede que vivenciem o prazer de praticar o lazer.

Atualmente são poucas as experiências de lazer em saúde mental. Ressaltamos a singularidade de cada um destes trabalhos, embora todos tenham em comum o objetivo de se constituírem num espaço de lazer.

\section{Histórico do Clube de Lazer e Cidadania Colônia}

Somente a partir do processo de desinstitucionalização realizado no IMASJM é que se tornou possível iniciar a construção do Clube de Lazer, visando contribuir para o rompimento dos pilares desta que se caracterizava até então como uma instituição total, limitante e restritiva que, assim como outros tantos asilos, se constitui enquanto espaço de empobrecimento e rigidificação das trocas sociais.

A primeira experiência de lazer para usuários dos serviços de saúde mental do IMASJM e da cidade do Rio de Janeiro ocorreu em 1996 quando foi inaugurado o Clube de Esquina, em Botafogo. Ele funcionava a partir de uma rede de instituições, entre elas o Programa de Residência do IMASJM; seu objetivo principal era: “... acompanhar os usuários de serviços de saúde mental em atividades que proporcionem alegria e descontração. O Clube facilitará novas trocas sociais e buscará desenvolver o companheirismo e a solidariedade" (IPUB/ UFRJ e IFB, 1996 apud Simone e Nascimento, 1999).

A avaliação que a equipe do IMASJM fez acerca da participação nas atividades de lazer no Clube de Esquina foi o baixo aproveitamento por parte dos 


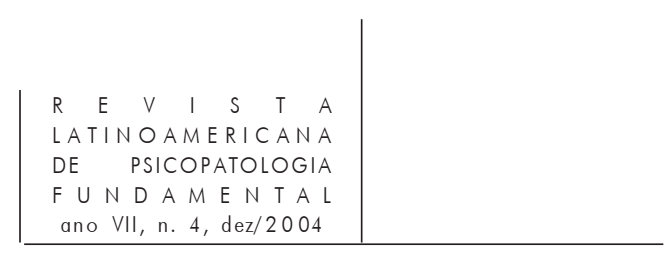

seus usuários em função da grande distância, da dificuldade de locomoção, resultando em uma reduzida participação. ${ }^{6}$

Em janeiro de 2000, o Clube de Lazer iniciou seu funcionamento como parte do Programa de Centro de Estudos do IMASJM. O Clube de Lazer teve, inicialmente, suas atividades desenvolvidas pela equipe de estagiários do Centro de Estudos, os Educadores do $\mathrm{MOVA}^{7}$ e a equipe da Rádio Comunitária em conjunto com uma Associação de Moradores. ${ }^{8}$

O Clube de Lazer veio em resposta à demanda dos usuários dos serviços do IMASJM. A partir de abril de 2002 algumas alterações foram feitas de acordo com a demanda da clientela e do processo de organização do próprio Clube. Dentre essas mudanças destacam-se a constituição de uma equipe fixa para o trabalho no Clube de Lazer, a regularidade do funcionamento em todos os sábados, a oferta de várias atividades distintas e simultâneas que possibilitem a escolha por parte dos usuários, além de passeios mensais.

Apresentamos uma tabela que indica o número de participantes de acordo com as atividades desenvolvidas no Clube de Lazer (tabela 1).

6. O IMASJM está localizado no bairro de Jacarepaguá, e o Clube de Esquina funciona no Campus da Praia Vermelha da UFRJ. A distância entre estes espaços é cerca de 40km, e ainda hoje é necessário pegar três ônibus para se realizar esse trajeto.

7. O MOVA é um movimento de alfabetização de adultos da Secretaria de Educação do Governo do Estado do Rio de Janeiro, que destina a cada um dos núcleos do IMASJM um educador para alfabetizar os usuários.

8. Existe na área do IMASJM cerca de doze Associações de Moradores, sendo que no ano de 2003, duas desenvolveram atividades em conjunto com o Clube de Lazer. 
No ano de 2002 freqüentaram as atividades do Clube uma média de 98 usuários. No ano de 2003, a média de participação por sábado subiu para 127 usuários, sendo desconsiderados os dias de passeio externo em que participa um número menor de freqüentadores do Clube.

\section{Parte III - O lazer enquanto objeto de estudo}

\section{O conceito de lazer}

Como vimos na introdução, lazer, de acordo com Dumazedier (1999), é um tempo disponível para a auto-satisfação.

A questão do tempo é essencial para a compreensão das práticas de lazer e para a própria constituição deste campo.

Como podemos pensar o tempo livre levando em conta que a clientela do IMASJM vive no ócio forçado da reclusão asilar? O que significaria lazer para essa população? O lazer se contraporia a quê, uma vez que a questão do trabalho não faz parte deste universo populacional? Além disso, dentro da questão do tempo, temos o fato de que a clientela do IMASJM apresenta, como nos aponta Lima et al. (2003) em Validação Transcultural da Escala de Avaliação de Limitações no Comportamento Social em média 65,8 anos de vida e 37,3 anos de internação.

Percebemos que a marcação do tempo, assim como a identidade dos usuários que residem no IMASJM, sofreu grandes transformações, dado o tempo de reclusão no espaço asilar. Ana Lúcia Santa Rosa (2003), em sua dissertação de mestrado Envelhecer sobre quatro paredes: uma experiência no Instituto Municipal de Assistência à Saúde nos aponta que:

Para os usuários entrevistados, passado e presente mesclam-se nos relatos, na medida em que não aparentam ter ciência de acontecimentos exteriores ao seu cotidiano direto, aparentemente retornando a um estado atemporal onde calendários e relógios são desnecessários, uma vez que se referem à temporalidade do mundo externo ao qual não mais pertencem. Como a vida institucional não favorece o contato dos usuários com a realidade exterior, parece haver perdido a referência do tempo mensurável, preservando, no entanto, a noção de tempo enquanto dado natural da natureza humana, refletindo um lapso do tempo. (p. 155)

Embora a presença da equipe de trabalho objetive a criação e a ampliação de laços sociais e temporais, ainda são as atividades básicas da vida diária, tais como a comida, o banho, o remédio e a hora de dormir que marcam o tempo e o cotidiano. No Clube de Lazer, os pacientes apontam a comida como um fator de 


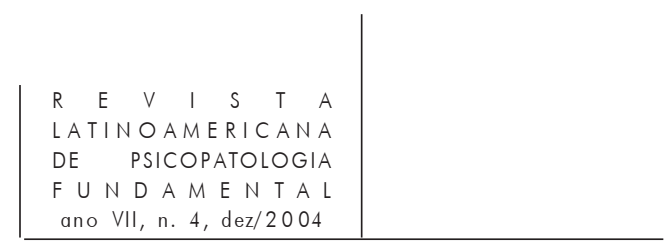

satisfação, referindo inclusive que a comida do clube é mais gostosa, muito embora seja a mesma oferecida pelo hospital. Isto seguramente se deve ao trabalho desenvolvido em torno da hora da alimentação: higiene das mãos, música apropriada, talheres próprios, pratos de louça, valorização do prazer da alimentação etc.

Um elemento que nos chama a atenção a partir das entrevistas realizadas no Clube de Lazer é o fato de os usuários saberem nomear o sábado como o dia do Clube, muito embora tenham dificuldade para nomear outros dias da semana. Poderíamos, neste sentido, dizer que o Clube de Lazer marca um diferencial no tempo da vida dessas pessoas.

Para os nossos usuários, o importante é que o sábado não é mais um dia de tempo livre, marcado pelo tripé: banho, remédio e hora da comida. O lazer é para eles um tempo ocupado, mas ocupado qualitativamente.

\section{A pertinência da aplicação do conceito de lazer ao campo da saúde mental}

Nesta parte do trabalho vamos cotejar a produção teórica sobre o lazer com alguns dos achados que encontramos através da aplicação dos questionários.

Para Dumazedier, na conceituação de lazer deve-se levar em conta os seguintes aspectos: caráter liberatório, caráter desinteressado, caráter hedonístico e caráter pessoal. Vamos estudá-los a seguir.

\section{Caráter liberatório - O lazer resulta de uma livre escolha}

Os pacientes são convidados pelas cuidadoras ${ }^{9}$ dos seus Núcleos a participar do Clube, mas a participação é voluntária. Eles tomam banho e vestem suas roupas limpas e arrumadas, muitas vezes sem a ajuda de terceiros, diferentemente do que ocorre durante a semana. Saem então dos Núcleos e se dirigem ao Clube. O que temos podido observar é que há uma mudança de postura dos pacientes nesse dia. O Clube não é visto e entendido como mais uma atividade hospitalar, mas sim um momento de "brincadeira". Para ilustrar, vejamos alguns fragmentos de entrevistas realizadas no Clube de Lazer em que destacamos algumas falas dos usuários a respeito do Clube:

9. A função de cuidadora se refere à realização de atividades nos Núcleos em conjunto com os pacientes que inclui aspectos do autocuidado e acompanhamento em atividades terapêuticas como cinema e grupos de trabalho, entre outras. Quatro cuidadoras, sendo uma de cada Núcleo, participam da equipe fixa do Clube há pelo menos dois anos como recreadoras. 
Jair tem 56 anos, nasceu no Jacarezinho, bairro da cidade do Rio de Janeiro, relata que sua primeira internação aconteceu por volta dos onze para doze anos de idade. Passou pelo circuito de internações até que chegou à Colônia, somando um total de 39 anos de internação. Passou por pelo menos dois núcleos do IMASJM. Participa do programa de geração de renda do IMASJM e está morando numa residência terapêutica.

E: O que você gosta de fazer no Clube? Qual atividade você gosta no Clube?

Jair: Assistir o pessoal dançar, eu não.

E: Você não dança?

Jair: Dançar, fico assistindo só assistir o pessoal.

E: Você gosta de ver as pessoas dançarem?

Jair: Gosto.

E: Mas por que você não dança Jair?

Jair: Não sei não tenho vontade de dançar não.

E: Que coisa mais além de dançar que você gosta no Clube? O que mais?

Jair: É muitas coisas, o pessoal, o pessoal diferente, o pessoal.

E: Se você não estivesse no Clube o que você estaria fazendo?

Jair: Eu não ia fazer nada.

E: Não ia fazer nada?

Jair: Não ia fazer nada. Oh, se eu vê televisão, eu vou dormir.

Célia reside em um Núcleo feminino, não sabe dizer há quanto tempo. É natural do Rio de Janeiro e após pensar um pouco relata ter nascido no ano de 1945 e não sabe dizer sua idade. Relata participar da "Oficina de fazer unha".

E: Se a senhora não estivesse no Clube de Lazer agora onde a senhora estaria?

Célia: Lá na seção.

E: Na seção, e qual é a seção que a senhora mora?

Célia: Lá no Teixeira Brandão, sentada no jardim.

E: Ah, lá sentada no jardim, fazendo o quê? Só sentada no jardim?

Célia: Esperando visita né, me levar embora.

Ana tem mais de 40 anos de idade e embora não saiba sua idade, sabe o dia e mês de seu aniversário. Está institucionalizada desde a sua infância tendo passado pela antiga creche, denominada de Faixa Azul, e, em seguida, vivido em pelo menos mais três unidades do IMASJM.

Atualmente mora em uma residência terapêutica dentro da Colônia, trabalha em um dos dispositivos de geração de renda que a Instituição oferece, e afirma que não sabe escrever nem contar. Ana recebe salário e se orgulha de ter cartão de banco. Freqüenta o Clube desde a sua criação. Afirma que não participa de 


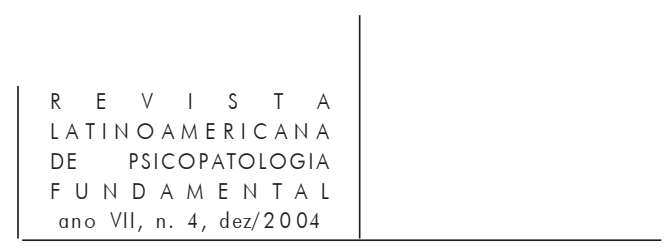

nenhuma oficina ou atividade na Instituição e é uma freqüentadora assídua do Clube de Lazer, sempre interessada nas atividades externas.

E: O que faz você vir ao Clube? Por que você vem ao Clube?

Ana: É pra distrair um pouquinho.

E: Pra distrair?

Ana: É.

E: Se você ficasse lá aonde você mora, o que você ficaria fazendo no sábado?

Ana: (peguei a vassoura ) um dia e ajudei o Cláudio.

E: Se você não viesse ao Clube você tava varrendo a casa?

Ana: Tava.

E: E aqui no Clube você varre também?

Ana: Não, aqui não varro não.

E: Aqui no Clube você trabalha na arrumação?

Ana: É ruim hein.

E: Ah, você riu e disse que é ruim hein. Aqui você gosta de quê?

Ana: Dançar, cantar.

E: Ouvir música, você gosta? Você disse que gosta do Clube pra distrair um pouco.

Ana: Só.

E: Ah, e o que mais você faz no Clube?

Ana: Ah, a gente fala.

Camila tem 30 anos, é solteira e moradora do Centro de Atenção Singularizada (CAS). ${ }^{10}$ Já passou por internações, no hospital Jurandyr Manfredini - pelo menos quatro vezes - e na Clínica Valença; não se recorda da data da sua primeira internação. Freqüenta as atividades do Caps Arthur Bispo do Rosário e do Cris, onde participa de oficinas de artesanato. Quando indagada sobre seus medicamentos relata todos os que utiliza.

E: Vou te fazer uma pergunta agora difícil heim. Por que você vem ao Clube? Qual o motivo maior de você vir ao Clube? Às vezes vem, vem todo sábado?

Camila: Olha eu acho que o Clube, (...) é um espaço de lazer.

E: De lazer?

Camila: A pessoa pode se ocupar, se integrar as pessoas eeeeee... eu gosto daqui.

E: Para você o que é lazer? Você falou um espaço de lazer. O que é lazer? Pra quem não soubesse o que é lazer o que você explicaria?

10. O Centro de Atenção Singularizada é uma ONG financiada pela FIA que abriga jovens portadores de transtornos mentais. 
Camila: É uma coisa legal onde vive as pessoas, onde a gente conhece as pessoas.

...

E: Camila, então deixa eu te perguntar outra coisa. Se você não tivesse vindo ao Clube hoje, o que você estaria fazendo hoje, sábado, se não estivesse no Clube?

Camila: Você quer que eu fale a verdade?

E: Pode falar a verdade.

Camila: Taria escutando walk men, fita.

E: Ouvindo música?

Camila: É.

E: Ah, no Clube você gosta de ouvir música?

Camila: Adoro.

E: O que você gosta mais no Clube? Qual a coisa que você gosta de fazer no Clube?

Camila: A presença de todos.

Lia reside no Núcleo Teixeira Brandão, aparenta ter aproximadamente 65 anos; embora não saiba dizer o ano de seu nascimento ressalta que o dia de seu aniversário é 20 de janeiro, dia de São Sebastião. Está internada a "um bocado de tempo". Lia não gosta de ser chamada pelo seu nome próprio e se apresenta com um segundo nome. É freqüentadora assídua do Clube de Lazer e tem por hábito chamar as mulheres que gosta de comadre.

E: Se você não estivesse no Clube de Lazer agora, onde você estaria?

Lia: Internada.

E: Internada?

Lia: É.

E: E fazendo o quê?

Lia: Fazendo cocô de perna abaixo com diarréia.

E: Pra você o que é lazer?

Lia: É bom.

E: É bom?

Lia: É.

E: É diversão? É brincadeira?

Lia: Tem muita amiga que respeita a gente, não são dado nem tarado.

2. Caráter desinteressado

Para Dumazedier,

No lazer, o jogo, a atividade física, artística, intelectual ou social não se acha a serviço de fim material ou social algum (...) se o lazer obedece parcialmente 


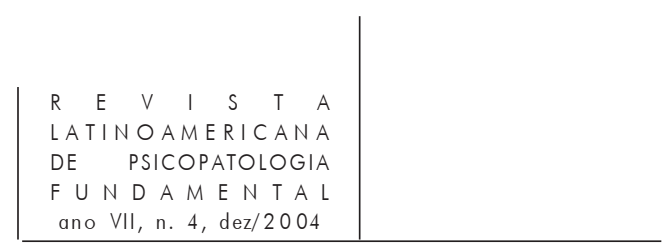

a um fim lucrativo, utilitário ou engajado, sem se converter em obrigação, não é mais inteiramente lazer. Torna-se lazer parcial, é conceituado como semilazer [...] o semilazer é uma atividade mista em que lazer é misturado a uma obrigação institucional. (1999, p. 95)

O Clube tem como objetivo produzir a autonomia, o autocuidado, o poder de decisão, a expansão dos laços afetivos e sociais e a qualidade de vida; no entanto esses objetivos partem dos técnicos. Os usuários não vão ao Clube com o intuito de se reabilitar, vão ao Clube se divertir, vão pela comida, pelas pessoas. O caráter parcial é de quem programa o Clube.

Podemos então conceitualmente localizar que o Clube é de lazer para os usuários e de semilazer para os técnicos. Estes estão trabalhando através do lazer na direção da Reabilitação Psicossocial dos clientes.

Apresentaremos alguns fragmentos colhidos da entrevista com as recreadoras do Clube de Lazer.

\section{- Recreadora Clara}

E: Através do Clube você já realizou alguma atividade ou passeio que você não havia experimentado ainda?

Clara: Já. É visitar assim, museus, é uma coisa que sozinha eu não sou assim de fazer, não gosto, não acho legal.

E: Qual foi o museu que você visitou?

Clara: Foi o museu Naif que nós fomos; é foi mais assim de coisa de museu. E: Foi bom para você, como é que foi para você estar lá naquele espaço?

Clara: Oh foi legal por isso, não sou muito de freqüentar museu. Gosto mais de sair e ficar à vontade, mas ali aquela experiência da gente está passeando e ficar mostrando aquela experiência do que estava se passando naquelas pinturas...

Clara: (...) sozinha eu sempre vou a praia sim. Mas a praia é um lugar que sozinha é diferente, você fica mais sentada não é muito de ficar na água e com elas tem que estar ali, você fica brincando, conversando e fica mais à vontade aproveita muito mais até do que você sozinha.

\section{- Recreadora Maria}

E: O que você acha do trabalho que você faz, como recreadora lá no Clube? Maria: Ah, eu acho legal, é um trabalho que eu gosto, me sinto bem fazendo, apesar de ser no sábado eu gosto de fazer. Acordo sábado com vontade de ir ao Clube. Tenho maior prazer de ir ao Clube, sempre gostei de trabalhar aos sábados. Eu entrei na Colônia pra trabalhar aos sábados. E gosto muito, chego lá na unidade eles estão me esperando feliz da vida. 
E: Como eles expressam essa felicidade?

Maria: Gente... assim, tem o Flávio que ele vem gritando o meu nome muito feliz e vem mostrando a todo mundo que eu estou chegando pra ir ao clube.

- Recreadora Joana

E: Através do Clube você já realizou alguma atividade algum passeio que você não havia experimentado, algum lugar que você não tinha conhecido?

Joana: Já, com certeza, muitos e não foi só um não.

E: Como é que foi para você estar nesses lugares?

Joana: O Pão de Açúcar, sim, o que me marcou mais, foi o Pão de Açúcar, né, que inclusive eu fui uma das que levantei aqui e pedi pra conhecer o Pão de Açúcar e graças a Deus nós conseguimos e fomos. E eu gostei muito, nunca tinha ido. Não conhecia e fiquei muito satisfeita de ter ido e foi muito bom, muito bom mesmo. O Pão de Açúcar foi um dos que mais marcaram pra mim, apesar que quando nós vamos a gente se divide entre o lazer e semilazer, como nós chamamos. Porque a gente fica de olho neles aí a gente procura usufruir um pouquinho como foi o meu caso que eu conheci, que eu nunca tinha ido e gostei muito de ter ido e mesmo sendo um semilazer pra mim foi um lazer e foi maravilhoso, foi inesquecível, foi muito bom.

E: E tem mais algum outro lugar sem ser o Pão de Açúcar que tenha te marcado?

Joana: Acho que foi o que me marcou mais, o Outeiro da Glória que não conhecia. Uma igreja muito bonita, gostei muito de ter ido, ainda mais que a gente viu um casamento uma coisa muito bonita lá, uma coisa muito chique, uma coisa maravilhosa gostei muito também.

- Recreadora Denise

E: Através do Clube você já realizou alguma atividade, passeio que você não havia experimentado antes?

Denise: Iiii..., vários, o Pão de Açúcar.

E: Como é que foi? Quais foram e como foram por ordem de prioridade.

Denise: Eu me senti muito importante (risos) nunca sonhei na minha vida em está colocando os pés no bondinho.

E: Por que?

Denise: Porque é caro, pra mim eu ir sozinha não posso, eu tenho filhos, é claro eu gostaria de proporcionar isto aos meus filhos, então as condições financeiras não dá. Eu adorei. Na igreja, lá no Outeiro da Glória foi muito bacana. Sinceramente, a não ser o museu do, ali, da Quinta da Boa Vista, na Quinta da Boa Vista eu passei ali quando eu era criança, no negócio de escola, tinha um museu, fora isso eu nunca tinha entrado em museu algum. 


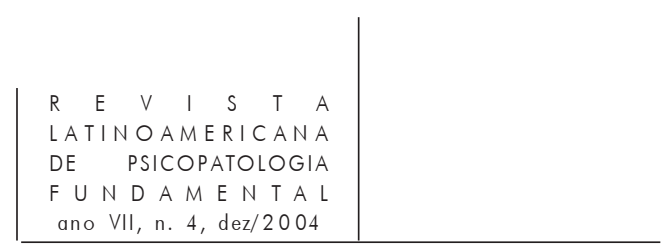

E: Por que?

Denise: Ai porque não dá para ir, não dá para ir, tem que fazer as coisas em casa, tem que fazer as coisas.

E: Hum.

Denise: E ali além de cuidar daquela igreja bonita famosa que todos falam, tive a oportunidade de entrar no museu, ver aquelas peças lá bonitas, aqueles santos, o rapaz falou um pouquinho de cada um. Tinha um casamento lá, que eu só vi coisa em novela

E: Como era esse casamento?

Denise: Ah pomposo, chique todo mundo de chapéu (risos). Ah muito bonito, só vi casamento de chapéu na novela. Mais um que eu também adorei foi na Marinha, aquele passeio de barco.

E: Como é que foi?

Denise: Ah, foi muito legal, eu nem ouvi o que a dona falou, ela estava falando ali, e eu estava viajando, pensando em mil e uma coisas. É como o trabalho está me proporcionando coisas que eu nem sonhava em fazer, nem sonhava, eu acho que através deste trabalho, não, eu tenho certeza eu cresci como pessoa, tô crescendo como pessoa, estou querendo melhorar, ter uma profissão, estudar, coisa que eu achava que não ia poder fazer mais. Depois que você casa, tem filhos, você vive para casa para os filhos, pro marido e pra mim esta parte de trabalho assim, estudar, querer ser alguém eu tinha esquecido e através desse emprego eu pude realizar muita coisa que eu achava que não era nem capaz de fazer.

3. Caráter hedonístico - A busca de um estado de satisfação é de fato a condição primeira do lazer

\section{Para Camargo,}

... em toda escolha de lazer, existe o princípio da busca do prazer, mesmo que a atividade inicie com um esforço, para se obter o relaxamento agradável ou a sensação posterior de estar em forma; ou que termine o tédio. (1992, p. 12)

Carlos relata ter nascido em Alagoas em 1944, e que tem hoje 57 anos. Veio para o IMASJM em 1973 onde permanece internado até hoje. Relata participar das atividades do Clube há uns três anos.

E: E por que o senhor vem ao clube?

Carlos: Venho para distrair mais vocês, ouvir música.

E: Ah, que legal. E se o senhor não estivesse aqui no clube de lazer agora, que o senhor estaria fazendo? 
Carlos: Não, pra ficar em casa não é bom não. Só dormir, dormir não é bom não.

E: Com certeza não.

Carlos: Não dá pra distrair né?

Paulo, tem 23 anos de idade, nasceu no dia 19 de abril de 1980. Paulo reside no CAS, que se localiza próximo ao IMASJM, não está ligado a nenhum serviço da Rede, exceto o Clube de Lazer aonde vem acompanhado por outros amigos.

E: Por que você vem ao Clube?

Paulo: Ué, porque eu venho pra me divertir um pouquinho, me distrair um pouquinho. É... comer uma outra coisa, me... ter outros tipos de atividades. E: Você acha então que o Clube é bom para fazer outras atividades?

Paulo: Acho.

E: E se você não estivesse no Clube aos sábados o que você faria?

Paulo: Aí eu ia estar lá em... eu tava naquela casa lá, no CAS lá, só no CAS lá.

E: Fazendo o quê?

Paulo: Trabalhando para as pessoas. Pelo menos eu passeando que já foi dito que a gente tinha que dá uma voltinha por aí, pela colônia. Assim... dá uma voltinha e eu faço isso, de vez em quando eu vou com meu amigo Pedro para soltar pipa em outros lugares, aí lá perto de casa na praça com meu amigo José e Roberto.

Elisa relata ter sido casada, seu aniversário é dia 19 de abril, embora desconheça o ano. Já participou do programa de geração de renda do IMASJM, mas atualmente está "encostada" devido a problemas de alergia. Relata que toma diazepam e remédio para pressão alta.

E: E por que você vem ao clube?

Elisa: Pra se divertir.

E: Pra se divertir. E para você o que é se divertir? O que é diversão?

Elisa: Escutar som, a gente vai ao passeio.

E: Isso que é diversão?

Elisa: É.

E: Você gosta de se divertir?

Elisa: Gosto.

E: Aqui no clube o que você gosta de fazer?

Elisa: Aqui da Colônia?

E: Aqui no Clube de Lazer, sábado, o que você gosta de fazer aqui? O que você faz?

Elisa: Eu fico armando aqueles brinquedos.

E: Dominó? 


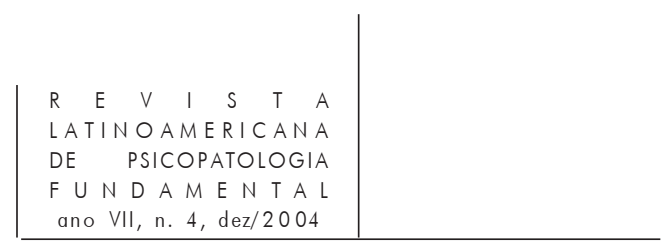

Elisa: Eu jogo dominó e fico armando aqueles brinquedos, consegui armar um caminhão de brinquedo.

E: Que mais você faz sábado aqui? O que você gosta?

Elisa: Eu gosto de arrumando a assembléia também.

E: Gosta? Por que você gosta da assembléia?

Elisa: Porque a assembléia fala coisas boas.

E: Por exemplo? O quê?

Elisa: Porque fala coisa boa.

E: Coisa boa? O que é coisa boa?

Elisa: Coisa boa é falar que a gente vai passear, falar que a gente vai passear, falar que a gente vai é andar, passear.

\section{Caráter pessoal}

\section{Para Dumazedier,}

Todas as funções manifestas do lazer respondem às necessidades do indivíduo, (...) abrindo um universo real ou imaginário do divertimento, autorizado ou interdito pela sociedade, permitindo que cada um saia das rotinas e dos estereótipos impostos pelo funcionamento dos organismos de base; abre o caminho de uma livre superação de si mesmo e de uma liberação do poder criador, em contradição ou em harmonia com os valores dominantes da civilização. (1999, p. 97)

A usuária Lia, que já identificamos anteriormente, pode nos apontar outros fatores que a motivam a ir ao Clube.

E: Lia, e por que você vem ao Clube de Lazer?

Lia: Eu...

E: Por que você vem ao Clube?

Lia: Eu gosto daqui.

E: Gosta. O que tem aqui que você gosta?

Lia: Tem o bingo, bingo vai ter que dia o bingo?

E: Aí eu não sei qual dia vai ter o bingo, mas só o bingo que você gosta?

Lia: Eu gosto de você, gosto da minha comadre, gosto da minha comadre.

Joaquim relata estar internado no IMASJM desde 1970, não sabe sua idade, mas sabe o ano de nascimento, 1924. Reside em um Núcleo masculino onde eram desenvolvidas atividades agrícolas. Gosta de criar músicas sobre as pessoas e tocar flauta; é freqüentador assíduo do Clube de Lazer.

E: E por que você vem ao clube, Joaquim?

Joaquim: Por que eu venho ao Clube? 
E: é.

Joaquim: Venho ao clube porque eu gosto de viajar.

E: Gosta de viajar?

Joaquim: Gosto de ver as farras aí.

Joaquim: Farreei muito lá, na, quando tinha festa na Nossa Senhora da Penha naquele arraial da Penha.

E: E se não tivesse o Clube de Lazer o que você estaria fazendo agora? Se você não estivesse aqui?

Joaquim: Eu queria que tivesse uma grande festa no agrícola.

E: E para você o que é o lazer?

Joaquim: Lazer?

E: É. Lazer é diversão, é brincadeira?

Joaquim: Se é brincadeira?

E: O que é lazer?

Joaquim: Lazer?

E: Isso.

Joaquim: É botar todo mundo pra farrear.

E: E quando está todo mundo farreando?

Célia, já apresentada anteriormente, relata:

E: E pra senhora o que é lazer? É diversão? É brincadeira?

Célia: O Clube né.

E: É o Clube?

Célia: O Clube tem uma porção de gente.

E: E das atividades do Clube quais as que a senhora mais gosta de fazer?

Célia: Pintar unha, pintar unha, passar maquiagem, batom.

E: Um passeio que a senhora gostaria de tá fazendo?

Célia: De novo na praia.

E: De novo pra praia?

Célia: É eu gosto só de praia, eu não gosto só assim pra Quinta ver os bichos, ao museu ver aquelas coisas.

E: A senhora gosta disso tudo?

Célia: Não, eu gosto só de praia.

E: Mas o que tem na praia que a senhora gosta tanto?

Célia: Tomar banho de mar, botar maiô, tomar banho de mar.

Alan reside no CAS e não participa de nenhuma atividade da Rede, exceto o Clube de Lazer. Gosta de cantar e tocar pandeiro que leva algumas vezes para 


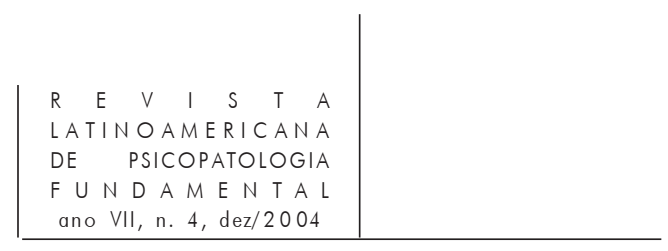

sua casa para ensaiar e vir se apresentar no Clube. Relata ter 19 anos, sabe o dia e mês de seu nascimento embora desconheça o ano.

E: E por que você vem ao Clube?

Alan: Para se divertir, para gostar das conversas boas, para compartilhar com os outros, para ter uma nova família unido na presença de Deus.

E: Legal! E se você não estivesse no Clube de Lazer, por exemplo, agora, se você não estivesse aqui agora, onde você estaria? O que você estaria fazendo?

Alan: Eu não estaria fazendo nada.

E: Estaria de bobeira, à toa?

Alan: À toa, mas agora eu estou muito feliz e muito alegre.

E: Pra você o que é se divertir? O que é brincar? O que é?

Alan: Se divertir é cantar, trazer o verdadeiro amor para a pessoa.

E: O que você mais gosta de fazer aqui no clube?

ALan: Eu gosto mais de cantar, dançar.

...

E: O que já teve aqui no clube que te marcou, que você gostou e que você falou: isso eu adorei. O que te marcou? Teve algum evento?

Alan: O que me marcou são as músicas, foi as festas.

E: E aquele dia que vocês se apresentaram você gostou?

Alan: Gostei, gostei do show, mas nós queremos apresentar um novo show com filmagem.

\section{Conclusão}

Destacamos duas frases ditas por freqüentadores do Clube em momentos determinados das atividades: "Sem o Clube de Lazer a gente estaria velho e andando de muletas" ${ }^{11} \mathrm{e}$ "O dia de hoje foi incomum de bom". ${ }^{12}$ Estas frases sintetizam o potencial do Clube de Lazer enquanto dispositivo inventado pela Reforma Psiquiátrica capaz de agenciar novas subjetividades, proporcionar prazer e experiências, que, em seu conjunto, são atividades clínicas em prol da vida e da saúde.

Acreditamos no Clube de Lazer como instrumento valioso de transformação do imaginário social a respeito da loucura no que se refere à periculosidade, necessidade de segregação e irrecuperabilidade da saúde.

11. Frase dita por João numa assembléia.

12. Mário exprimindo sua opinião sobre o passeio ao Museu Internacional de Art Naif. 
SAÚDE MENTAL

ano VII, n. 4, dez/2004

Levamos em conta o que assinala Saraceno (1996), para quem a reabilitação

... implica uma mudança total de toda a política de serviços de saúde mental, são os programas através dos quais tais políticas se aplicam, se realizam, e são estas que têm que ser modificadas. Por isso, reabilitação engloba a todos nós profissionais e a todos os atores do processo de saúde-doença, ou seja, todos os usuários, todas as famílias dos usuários e finalmente a comunidade inteira. (p. 92)

Mais do que isto, o compromisso com a reabilitação psicossocial implica experimentarmos novas saídas para velhos impasses; ousar transformar instituições onde predominavam muros. Trata-se, no caso, de se pensar a aplicabilidade dos conceitos de lazer - oriundos do mundo do trabalho - na área da saúde mental.

Pudemos acompanhar neste trabalho como a Reforma Psiquiátrica é, historicamente, o movimento que levou mais adiante a crítica radical do abandono e do asilo, propondo a luta em prol da desinstitucionalização dos doentes mentais. Nesta direção é que surgiram as iniciativas de Clube de Lazer como estratégia nesta luta.

O IMASJM está sendo desconstruído enquanto lugar de abandono e o Clube de Lazer e Cidadania Colônia participa dessa iniciativa.

Um dos aspectos a serem destacados na teoria do lazer é o do caráter de lazer para os usuários e o de semilazer para os técnicos. Ou seja, a equipe também usufrui do lazer, só que de forma diferenciada. As entrevistas com as recreadoras evidenciaram o acerto da escolha destas entre as pessoas da comunidade. Sublinhamos que as recreadoras não dispõem de uma formação técnica acadêmica no campo da saúde. Elas foram escolhidas entre pessoas da comunidade que residem próximo ou dentro do IMASJM.

Localizado nos limites de uma instituição em processo de desconstrução, o Clube não poderia deixar de levar em consideração a questão do espaço. Os passeios desenvolvidos pelo Clube fazem parte da estratégia de desinstitucionalização, ajudando no resgate da história de vida de cada indivíduo.

A saída que os usuários realizam em cada sábado do Núcleo para o Clube deixa claro para os técnicos a felicidade dos clientes expressa em sorrisos quando vêem a Kombi chegar. A circulação, nestes momentos, se dá quase no mesmo plano geográfico, porém tão distante quando pensamos na dimensão humana. Trata-se de oferecer a possibilidade de deslizamento da lógica centrada na doença para uma ética do prazer, do compartilhamento, do acolhimento; ou seja, da impossibilidade para a afirmação através do exercício do lazer.

O Clube de Lazer proporciona também a ampliação do conhecimento e do reconhecimento da cidade, e, em decorrência, gera o aumento da contratualidade nestes espaços. O que tem além dos muros? Como é a minha cidade? 


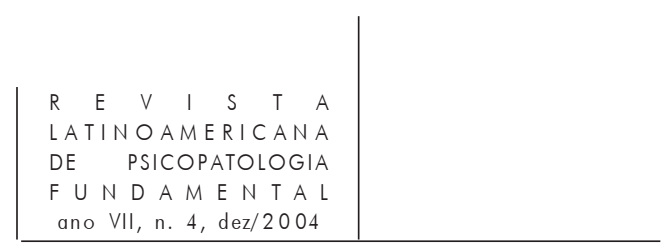

Para alguém tomar consciência de si, necessita tomar consciência do mundo.

Acreditamos, como Milton Santos (2000), na possibilidade de se produzir um lazer com "sensibilidade popular" que não compactue simplesmente com o lazer comercial.

... trata-se de salvaguardar e potencializar a sociodiversidade, que acompanha e qualifica a diversidade dos lugares, dos quais constitui, ao mesmo tempo, atributo e riqueza (...) Trata-se, a partir disso, da construção de um mundo novo, com a busca da plenitude, onde a vida seja vivida como troca e onde o qualitativo seja dominante, permitindo que se instale no planeta o homem integral. O lazer pode ser um dado dessa grande transformação, desde que não seja considerado como fenômeno isolado. (...) é nosso dever pensar numa outra fórmula, mais generosa, que o inclua na humanidade. (p. 37)

Buscamos, na esfera da saúde mental, refletir sobre qual deve ser o sentido, hoje, das atividades de lazer e sobre o que nos é oferecido. Um complicador desta questão nos aponta Raquel Rolink (2000) quando afirma que

A dimensão pública vai perdendo cada vez mais sua dimensão política de contrato social e acaba reduzindo-se à administração do trânsito, da rede de água e de esgoto etc. Na verdade, o espaço público vai diminuindo ao ser capturado e privatizado, restando apenas e tão-somente aquele necessário para a circulação de mercadorias, inclusive das mercadorias humanas; esvazia-se a dimensão coletiva e o uso multifuncional do espaço público, da rua, do lugar de ficar, de encontro, de prazer, de lazer, de festa, de circo, de espetáculo, de venda. Assim, funções que recheavam o espaço público e lhe davam vida migraram para dentro de áreas privadas, tornando-se, em grande parte, um de circulação. (p. 134)

Realizamos nosso trabalho considerando que a cidade, o bairro e a comunidade podem construir um projeto em sintonia com os princípios da Reforma Psiquiátrica. Consideramos isto um imperativo quando se leva em conta a história da instituição e o seu perfil atual de ocupação. O Clube de Lazer atua num bairro que se construiu nos limites de uma instituição asilar operacionalizando os referenciais da teoria do lazer num dispositivo inventado na luta e para as lutas empreendidas pela Reforma Psiquiátrica.

\section{Referências}

Amarante, Paulo Duarte de Carvalho. Psiquiatria social e colônia de alienados no Brasil (1830-1920). 1982. 129 p. Dissertação (mestrado em Medicina Social). Universidade do Estado do Rio de Janeiro. 
Loucos pela vida: a trajetória da reforma psiquiátrica no Brasil. Rio de Janeiro: SDE/ENSP, 1995.

BRASIL. Portaria no 224, de 29 de janeiro de 1992. Legislação em Saúde Mental 19902000. Ministério da Saúde. Série E - Legislação em Saúde, n. 4. Brasília, 2000, p. 57.

Portaria no 336, de 19 de fevereiro de 2002. Legislação em Saúde Mental 19902002. Ministério da Saúde. Série E - Legislação em Saúde, Brasília, p. 92.

Camargo, Luiz Octávio Lima. O que é lazer? São Paulo: Brasiliense, 1992.

Cavalcanti, Maria Tavares. O tear das cinzas. 1992. 356 p. Dissertação (mestrado em Psiquiatria). Instituto de Psiquiatria da Universidade Federal do Rio de Janeiro.

Dumazedier, Joffre. Sociologia empírica do lazer. São Paulo: Perspectiva, 1999.

Goffman, Erving. Manicômios, prisões e conventos. 6⿳亠 ed. São Paulo: Perspectiva, 1999.

Goldberg, Jairo. Reabilitação como processo - O centro de atenção psicossocial CAPS. In: Pitta, Ana Maria Fernandes (org.). Reabilitação psicossocial no Brasil. São Paulo: Hucitec, 1996. p. 33-47.

Gomes, Maria Paula Cerqueira. A política de saúde mental na cidade do Rio de Janeiro. 1999. 319 p. Tese (doutorado em Saúde Mental). Universidade Federal do Rio de Janeiro.

LimA, Lúcia et. al. Validação transcultural da escala de avaliação de limitações no comportamento social. SBS - BR. Revista de Psiquiatria Clínica, v. 30, n. 4, p. 92-138, 2003.

Masi, Domenico de. A economia do ócio. In: Masi, Domenico de (org.). A economia do ócio. Rio de Janeiro: Sextante, 2001. p. 11-45.

Milagres, André Luís Duval. Porta de saída do asilo: cotidiano, narrativa e subjetividade nas residências terapêuticas em saúde mental do IMAS Juliano Moreira. 2002. 174 p. Dissertação (mestrado em Ciências Sociais). Universidade do Estado do Rio de Janeiro.

Pitta, Ana Maria Fernandes. O que é reabilitação psicossocial. In: Pitta, Ana Maria Fernandes (org.). Reabilitação psicossocial no Brasil. São Paulo: Hucitec, 1996. p. $19-26$.

Rolnik, Raquel. O lazer humaniza o espaço urbano. In: Lazer numa sociedade globalizada: Leisure in a Globalized Society. São Paulo: SESC/ WLRA, 2000. p. 179- 84.

SAnta Rosa, Ana Lúcia. Envelhecer sobre quatro paredes: uma experiência no Instituto Municipal de Assistência à Saúde Juliano Moreira. 2003. 177p. Dissertação (mestrado em Medicina Social). Universidade Estadual do Rio de Janeiro.

Santos, Milton. Lazer popular e geração de empregos. In: Lazer numa sociedade globalizada: Leisure in a Globalized Society. São Paulo: SESC/ WLRA, 2000. p. 31-7.

SARACEno, Benedeto. Reabilitação psicossocial: uma estratégia para a passagem do 


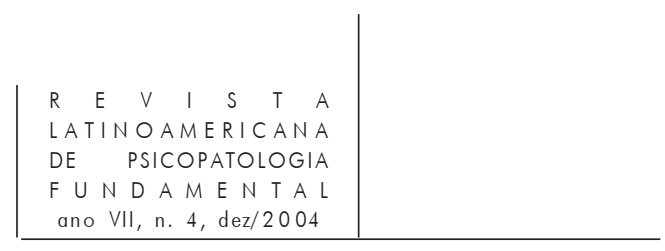

milênio. In: Pitta, Ana Maria Fernandes (org.). Reabilitação psicossocial no Brasil. São Paulo: Hucitec, 1996. p. 13-8.

Libertando identidades: da reabilitação psicossocial à cidadania possível. Belo Horizonte/Rio de Janeiro: Te Cora Editora/ Instituto Franco Basaglia, 1999.

Schechtman, Alfredo et al. Política de saúde mental no Brasil. Cadernos IPUB. Rio de Janeiro, n. 3, p. 9-11, 1999.

Tykanori, Roberto. Contratualidade e reabilitação psicossocial. In: PitTA, Ana Maria Fernandes (org.). Reabilitação psicossocial no Brasil. São Paulo: Hucitec, 1996. p. 55-9.

\section{Resumos}

El programa "Club de Entretenimiento y Ciudadanía Colonia" funciona desde enero de 2000 en el Instituto Municipal de Asistencia a la Salud Juliano Moreira IMASJM, de la ciudad de Río de Janeiro. Es un dispositivo creado a partir de los principios que orientan el movimiento de reforma psiquiátrica en el Brasil. Él está incluido en los diversos servicios que se hicieron necesarios a partir del movimiento de desinstitucionalización psiquiátrica en nuestro país. Este trabajo busca aplicar la teoría sociológica del ocio - apoyada en Joffre Dumazedier, Domenico de Masi y Milton Santos - en el campo de la salud mental. Son definidos el ocio (o tiempo libre), el medio ocio y la interacción significativa con la calidad de vida. Se efectúa un abordaje teórico y una investigación cualitativa la cual analiza las características del ocio para las personas que sufren problemas psiquiátricos y para el equipo de atención.

Palabras claves: Ocio, reforma psiquiátrica, rehabilitación, intervención social

Le Club de Loisir et de Citoyenneté Colônia fonctionne depuis janvier 2000 à l'Institut Municipal d'Assistance à la Santé Juliano Moreira - IMASJM, à Rio de Janeiro, et est un dispositif créé sur les principes qui guident le mouvement de réforme psychiatrique au Brésil. Il fait ainsi partie des divers services et pratiques qui devinrent nécessaires à partir du mouvement de désinstitutionalisation psychiatrique dans notre pays. Ce travail cherche à appliquer la théorie sociologique du loisir-présente chez. des auteurs tels que Joffre Dumazedier, Domenico de Masi et Milton Santos -, dans le domaine de la santé mentale. Le loisir et le semi-loisir y sont définis en soulignant leur rôle au sein de la société. On y trouvera un abordage théorique et une recherche qualitative analysant les caractéristiques du loisir pour les usagers et les membres de l'équipe.

Mots clés: Loisir, reforme psychiatrique, réhabilitation psychosociale, service extrahospitalier 
SAÚDE MENTAL

ano VII, n. 4, dez/2004

The Colônia Leisure and Citizenship Club has been open since January 2000 at the Juliano Moreira Municipal Health Institute in Rio de Janeiro. It was set up according to the principles on which the Brazilian movement for psychiatric reform is based. The club is related to various services and practices required for the movement toward non-institutionalization that has been taking place in Brazil. This study aims at applying the sociological theory of leisure, developed by authors such as Joffre Dumazedier, Domenico de Masi and Milton Santos, to the field of mental health. Leisure and semi-leisure are defined and their role in society is highlighted. This theoretical approach is presented, as well as qualitative field research that analyzes the characteristics of leisure from the point of view of both users and staff members.

Key words: Leisure, psychiatric reform, psychosocial rehabilitation, outpatient clinic

Versão inicial recebida em agosto de 2004

Aprovado para publicação em novembro de 2004 